\title{
Color remediation of chemimechanical pulping effluent using combination of enzymatic treatment and Fenton reaction
}

\begin{abstract}
This research investigated the efficiency of Advanced Oxidation Processes, Enzymatic treatment, and combined enzymatic/AOPs sequences on color remediation of CMP pulp and paper mills effluent. Regarding enzymatic treatment two kinds of fungal enzymes; Laccase (EC: 1.10.3.2) from Terametes Versicolor and Versatile Peroxidase (EC: 1.11.1.7) from Bjerkandera adusta were chosen and applied. Also, the effect of external mediator on the enzyme based degradations was studied. It was found that both VP from Bjerkandera adusta and Laccase from Terametes versicolor decolorized the deep brown effluent to a clear light yellow solution. It has been found that, concomitant use of enzymes and photo-Fenton process produces a considerable effect on color remediation. The data analysis of sequence treatment indicated that, chemical treatment after the enzymatic stage (photo-Fenton as a post treatment unit) yield a better performance for the CMP effluent.
\end{abstract}

Keyword: CMP pulp; Advanced Oxidation Processes (AOPs); Fenton; Enzymatic treatment; Versatile Peroxidase; Laccase 